\title{
Cisto ósseo aneurismático orbitário - Estudo clínico- patológico: relato de caso
}

\author{
Aneurysmal bone cyst of the orbit - A clinicopathological study: case report
}

\author{
Eduardo F. Marback ${ }^{1}$ \\ Murilo Neves ${ }^{2}$ \\ Roberto L. Marback ${ }^{3}$
}

\section{RESUMO}

O cisto ósseo aneurismático orbitário é doença rara, usualmente acomete pacientes jovens e é causada por alterações hemodinâmicas intra-ósseas. Relatamos um caso de cisto ósseo aneurismático orbitário, encaminhado com suspeita clínica e radiológica de cisto dermóide, comentando seus aspectos clínicos e anátomo-patológicos.

Descritores: Órbita/patologia; Cistos ósseos aneurismáticos; Cistos ósseos aneurismáticos/ patologia; Cistos ósseos aneurismáticos/diagnóstico; Cistos ósseos aneurismáticos/ cirurgia; Relatos de casos [Tipo de publicação]

\section{INTRODUCÃO}

O cisto ósseo aneurismático (COA) é lesão rara que mais freqüentemente afeta metáfises de ossos longos e vértebras de pacientes jovens. $\mathrm{O}$ envolvimento de ossos do crânio acontece em apenas 1 a $2 \%$ dos casos, sendo a ocorrência na órbita ainda mais rara. Em aproximadamente $1 / 3$ dos casos de COA este existe em associação a outras doenças ósseas, nos 2/3 restantes a lesão é um achado isolado ${ }^{(1-5)}$.

O objetivo deste trabalho é descrever um caso de COA orbitário, encaminhado com a suspeita diagnóstica de cisto dermóide.

\section{APRESENTAÇÃO DO CASO}

Paciente masculino, 21 anos, encaminhado com suspeita clínica e radiológica de cisto dermóide na órbita esquerda. Queixava-se de episódio doloroso associado à inflamação de pálpebra superior esquerda há um mês, com melhora parcial após uso de antiinflamatório não hormonal. Refere ter notado abaulamento na região lateral da órbita esquerda há muitos anos, com acentuação no último mês.

Ao exame apresentava visão igual a 1,0 em ambos os olhos. Havia exoftalmo de 3 milímetros à esquerda, além de leve deslocamento inferior e medial do globo ocular (Figura 1A). Notava-se abaulamento da parede lateral da órbita à esquerda, sem massa palpável. Não havia outros achados anormais ao exame. Trazia tomografia computadorizada (TC) e ressonância nuclear magnética (RNM) das órbitas, que revelavam lesão hipodensa, exibindo nível líquido, ocupando parte dos ossos zigomático, frontal e esfenóide à esquerda, com projeção para cavidade orbitária, deslocando medialmente as estruturas orbitárias e causando retificação da esclera lateralmente (Figura 1B).

O paciente foi submetido à orbitotomia lateral. Durante a remoção do arco zigomático, que apresentava espessura bastante diminuída, houve 


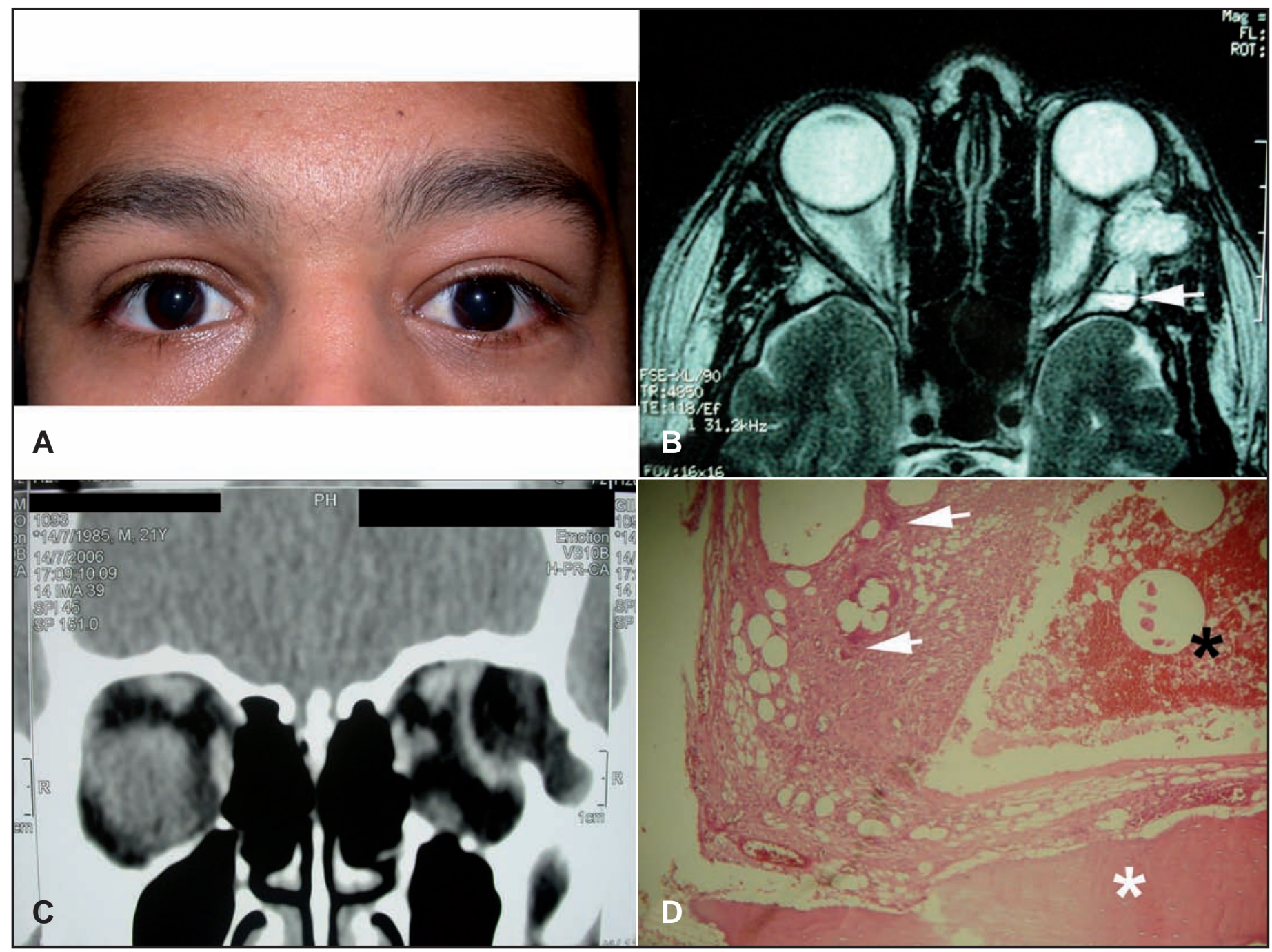

Figura 1 - A) Foto clínica. Leve aumento de volume em região súpero-externa da órbita esquerda; B) Ressonância nuclear magnética (T2). Notase em corte axial, lesão em zigomático esquerdo, exibindo nível líquido (seta) e deslocando o conteúdo orbitário medialmente; C) Tomografia computadorizada. Em corte coronal, observa-se imagem cística, com maior componente intra-ósseo, exibindo nível líquido e projetando-se para a órbita lateral esquerda; D) Microfotografia. Presença de áreas hemorrágicas (asterisco preto) e tecido fibrovascular exibindo células gigantes (setas brancas), em osso zigomático (asterisco branco) (hematoxilina eosina 100X).

drenagem de líquido de coloração castanha em grande quantidade. A cavidade óssea foi curetada com remoção de todo o tecido de aspecto anormal.

O estudo anátomo-patológico revelou tecido ósseo com presença de múltiplos espaços císticos, preenchidos por hemácias, sem cobertura endotelial. Separando os cistos, existiam septos contendo fibroblastos alongados e células gigantes multinucleadas (Figura 1D). O diagnóstico final foi de COA orbitário. O paciente evoluiu bem, não apresentando sinais de recidiva no controle radiológico após seis meses de acompanhamento.

\section{DISCUSSÃO}

O COA é uma doença rara, especialmente nos ossos da órbita $^{(1-3)}$. Em uma revisão da literatura em 2002, Cakirer e cols encontraram 18 casos descritos na literatura de língua inglesa ${ }^{(4)}$. Destes, um caso era secundário à displasia fibrosa $\mathrm{e}$ nos demais o COA foi um achado isolado. No mesmo artigo, o COA orbitário, citado como lesão que acomete jovens, com apenas dois pacientes maiores de 20 anos ao diagnóstico ${ }^{(4)}$. Já na revisão de Menon e colaboradores, que inclui casos publicados em outros idiomas, foram encontrados 22 relatos de COA da órbita ${ }^{(5)}$. O teto da órbita é descrito como a localização mais comum do COA orbitário, com 13 de 22 casos relatados, sendo o osso zigomático ou a parede lateral, acometidos em apenas $5 \operatorname{casos}^{(5)}$. Dentre as outras doenças que podem associar-se ao COA cita-se o tumor de células gigantes do osso, condroblastoma, osteoblastoma, hemangioma, hemangioendotelioma, doença de von Recklinghausen e fibroma condromixóide $^{(1-6)}$. Além destas doenças, em praticamente metade dos casos de COA extracranianos existe relato de trauma 
prévio ao aparecimento da lesão ${ }^{(2-3)}$. Já na órbita, a associação entre COA e trauma prévio é pouco freqüente ${ }^{(5-6)}$.

Usualmente os pacientes apresentam-se com proptose, de início recente, na maioria das vezes indolor e sem sinais inflamatórios, embora em alguns casos hemorragia intralesional súbita resulte em edema e dor devido à distensão do periósteo ${ }^{(6)}$. Achados associados incluem distúrbios da motilidade ocular, diplopia e outros sintomas compressivos ${ }^{(1,4-5,6-9)}$.

A patogênese do COA parece estar relacionada a distúrbios da circulação intra-óssea. O mecanismo básico parece ser o aumento da pressão venosa ${ }^{(2-3)}$. Este pode ocorrer após um episódio de trombose ou formação de uma fístula artério-venosa que levam à erosão, remodelamento e reabsorção óssea, formação de espaços vasculares dilatados e indução de processo reparador do osso ${ }^{(2-3)}$. Tal teoria é compatível com o aspecto anátomo-patológico típico do COA, que se caracteriza pela presença de múltiplos espaços vasculares sem revestimento endotelial. Estes espaços císticos possuem conteúdo hemorrágico e são separados por septos compostos por fibroblastos com células gigantes, macrófagos e tecido de granulação ${ }^{(2-3)}$.

O COA apresenta ao estudo pela TC aspecto de lesão cística, freqüentemente exibindo pequenas projeções e nível líquido, este secundário à diferente densidade dos componentes da sedimentação hemorrágica. Usualmente o osso acometido encontra-se afinado. Após a injeção de contraste endovenoso, nota-se realce da cápsula e septos fibrosos. A RNM pode adicionar informações nos casos em que existe a suspeita de erosão intracraniana, na qual a dura usualmente encontra-se preservada $^{(4-5)}$.

O tratamento consiste da remoção cirúrgica da lesão com curetagem de todo tecido afetado. Não encontramos, na literatura pesquisada, descrição de recidiva da lesão orbitária após a excisão cirúrgica ${ }^{(1-5,6-9)}$.

O caso em questão chama a atenção por ter sido encaminhado com a suspeita clínica e radiológica de cisto dermóide. Tal fato deve ter sido baseado no tempo de sintomatologia impreciso e aparentemente longo, associado ao aspecto aos exames de imagem e a faixa etária do paciente. Os cistos dermóide orbitários apesar de serem muito mais freqüentes que o COA, possuem achados radiológicos que podem se sobrepor aos destes. Corroborando esta impressão, encontramos o trabalho de Chawda e Moseley, que estudando os aspectos radiológicos de 160 casos de cistos dermóides orbitários, com confirmação anátomo-patológica, encontraram envolvimento ósseo, como afinamento ou erosão, em $85 \%$ dos $\operatorname{casos}^{(10)}$. Tais achados são também característicos dos $\mathrm{COA}^{(4)}$. Já o envolvimento da órbita lateral, foi encontrado em $71 \%$ dos casos de cisto dermóide, enquanto que no COA esta localização não chega a $25 \%$ dos casos. Trazendo mais confusão ao diagnóstico diferencial entre as duas lesões, o nível líquido tão freqüente no COA, pode ser visto em $5 \%$ dos cistos dermóides ${ }^{(4,10)}$.

Em suma, o COA é uma lesão rara, de pacientes jovens, mais freqüentemente visto como achado isolado, embora possa ser secundário a outras doenças ósseas. $\mathrm{O}$ tratamento é cirúrgico não havendo relatos de recidiva na órbita. A lesão pode simular, clínica e radiologicamente o cisto dermóide, sendo o estudo anátomo-patológico fundamental para o correto diagnóstico.

\section{ABSTRACT}

Aneurysmal bone cyst of the orbit is a rare disease that usually affects young patients and is caused by osseous hemodynamic alterations. We report a case of aneurysmal bone cyst of the orbit, referred to us as a dermoid cyst, discussing its clinical and histopathological aspects.

Keywords: Orbit/pathology; Bone cysts, aneurismal; Bone cysts, aneurismal/pathology; Bone cysts, aneurismal/diagnosis; Bone cysts, aneurismal/surgery; Case reports [Publication type]

\section{REFERÊNCIAS}

1. Johnson TE, Bergin DJ, McCord CD. Aneurysmal bone cyst of the orbit. Ophthalmology. 1988;95(1):86-9

2. Martinez V, Sissons HA. Aneurysmal bone cyst. A review of 123 cases including primary lesions and those secondary to other bone pathology. Cancer. 1988;61(11):2291-304.

3. Biesecker JL, Marcove RC, Huvos AG, Miké V. Aneurysmal bone cysts. A clinicopathologic study of 66 cases. Cancer. 1970;26(3):615-25.

4. Cakirer S, Cakirer D, Kabukcuoglu F. Aneurysmal bone cyst of the orbit: a case of rare location and review of the literature. Clin Imaging. 2002;26(6):386-91.

5. Menon J, Brosnahan DM, Jellinek DA. Aneurysmal bone cyst of the orbit: a case report and review of literature. Eye. 1999;13(Pt 6):764-8.

6. Garrity JA, Henderson JW. Aneurysmal bone cyst. In: Garrit JA. Henderson's Orbital Tumors. 4th ed. Philadelphia: Lippincott Williams \& Wilkins; 2007. p.90-3.

7. Yuen VH, Jordan DR, Jabi M, Agbi C. Aneurysmal bone cyst associated with fibrous dysplasia. Ophthal Plast Reconstr Surg. 2002;18(6):471-4

8. Borges G, Guerreiro MM. [Aneurysmal bone cyst of the orbit: report of a case] Arq Neuropsiquiatr. 1986;44(3):293-5. Portuguese.

9. Chemale IM, Torres L, Schmidt F, Azevedo MB. Cisto ósseo aneurismático orbitário: relato de um caso. J Bras Neurocir. 1989;1(1):23-6.

10. Chawda SJ, Moseley IF. Computed tomography of orbital dermoids: a 20-year review. Clin Radiol. 1999;54(12):821-5. 